\title{
Integrating TRIZ and Taguchi's Method in the Optimization of Processes Parameters for a Bin shelving
}

\author{
Ying-Hsiang Lin ${ }^{1, a}$, Kai-Yi Hsueh ${ }^{2, b}$, Chia-Pao Chang ${ }^{3, c^{*}}$ and Chien-Yu Lu ${ }^{4, d}$, \\ ${ }^{1,2,4}$ Department of Industrial Education and Technology, National Changhua University of Education, \\ Changhua, Taiwan, R.O.C \\ ${ }^{3}$ Department of Industrial Engineering and Management, National Chin-Yi University of Technology, \\ Taichung, Taiwan, R.O.C. \\ a3150316@yahoo.com.tw, ${ }^{\mathrm{b}}$ lab402aa@gmail.com, ${ }^{\mathrm{c}}$ chiapc@ncut.edu.tw, ${ }^{\mathrm{d}}$ lab402bb@gmail.com \\ ${ }^{*}$ Corresponding author
}

Keywords: Bin shelving; TRIZ; Taguchi's method; Process capability index (Cpk.)

\begin{abstract}
A bin shelving is one of the most popular furniture for storage. It not only stows materials effectively, but also increases vertical space while storing materials. It's very important to think about the load of every layer of a bin shelving. Every loading point of a bin shelving will affect the total load of the layer, structure and stability of racks. The parameter design method integrated with TRIZ and Taguchi's Method to find optimal parameters combination of every loading point of each layer was proposed. Experimental results show that the Cpk had increased from 0.53 to 1.12 . The $\mathrm{Cpk}$ value increased significantly to the standard that will contribute to process stability and quality control.
\end{abstract}

\section{Introduction}

People are usually troubled by how to stow materials effectively. A bin shelving showed as fig. 1 is often used in a house or a warehouse for space saving. There are many kinds of cabinets used to collect articles, but most of them have the same problem about occupying too much space and not easy to move. A bin shelving can be used to add the vertical space utilization, and moved easily. Therefore, the loading points of every layer are very important to affect total structure of the rack to be stable or not.

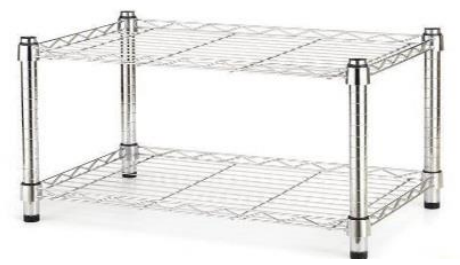

Figure 1. A typical bin shelving

TRIZ is a useful tool to solve problem. Lin and Chang focus on TRIZ to solve all kinds of problems successfully [1] [2]. Taguchi's Method can improve process and manufacturing quality by using fewer data analysis. There are many scholars such as Lee et al. (2007), Hong (2012) and Chan et al. (2015) plunge into this field with immense zeal[3][4][5]. Parameters combination is optimized by analyzing tools to reduce product deviation and improve process capability, product quality and stability in this research.

\section{Literature Review}

TRIZ was developed by the Soviet inventor and science-fiction author Genrich Altshuller and his colleagues, beginning in 1946. In English the name is typically rendered as "the theory of inventive problem solving"[6] [7]. TRIZ presents a systematic approach for understanding and defining 
challenging problems. It can systematically apply many useful tools and the strategies to find superior solutions that overcome the need for a compromise [8].

Taguchi methods are statistical methods, or sometimes called robust design methods, developed by Genichi Taguchito improve the quality of manufactured goods, and more recently also applied to engineering, biotechnology, marketing and advertising. Taguchi's work includes three principal contributions to statistics: (1) A specific loss function. (2) The philosophy of off-line quality control; and (3) Innovations in the design of experiments [9].

Process Capability Index (Cpk) is a statistical measure of process capability: the ability of a process to produce output within specification limits. Process Capability Index is usually applied as a tool to monitor quality and evaluate whether the process capability has reach standard or not. The Cpk level is showed as table 1.

Table 1. Level of Process Capability Index Cpk

\begin{tabular}{|c|c|c|}
\hline Level & Cpk value & Quality levels \\
\hline A & $1.67 \leq \mathrm{Cpk}$ & Excellent \\
\hline B & $1.33 \leq \mathrm{Cpk} \leq 1.67$ & Satisfactory \\
\hline $\mathrm{C}$ & $1.00 \leq \mathrm{Cpk} \leq 1.33$ & Capable \\
\hline $\mathrm{D}$ & $0.67 \leq \mathrm{Cpk} \leq 1.00$ & Inadequate \\
\hline $\mathrm{E}$ & $0 \leq \mathrm{Cpk} \leq 0.67$ & Poor \\
\hline
\end{tabular}

\section{Case Study}

Define - We define the load standard is $10 \mathrm{KG}$ by previous experience and test.

Measure - 30 pieces random sampling data are made from cooperated company as shown in table 2.

Table 2. 30 PCS data from loading point of a bin shelving (before improved)

\begin{tabular}{|c|c|c|c|c|c|}
\hline 9.4 & 9.8 & 10 & 10.6 & 10 & 10.2 \\
\hline 9.2 & 9.8 & 10 & 9.6 & 9.4 & 10 \\
\hline 10 & 9.8 & 10.2 & 10 & 10.2 & 9.8 \\
\hline 10 & 9.8 & 10 & 10 & 10.2 & 9.8 \\
\hline 10.4 & 10 & 9.6 & 10.2 & 10.2 & 9.6 \\
\hline
\end{tabular}

When we apply Minitab package to calculate Process Capability Index, the Cpk $=0.45<1.33$. It means that process capability is not sufficient and unstable. The whole process has much space to improve shown as Fig. 2.

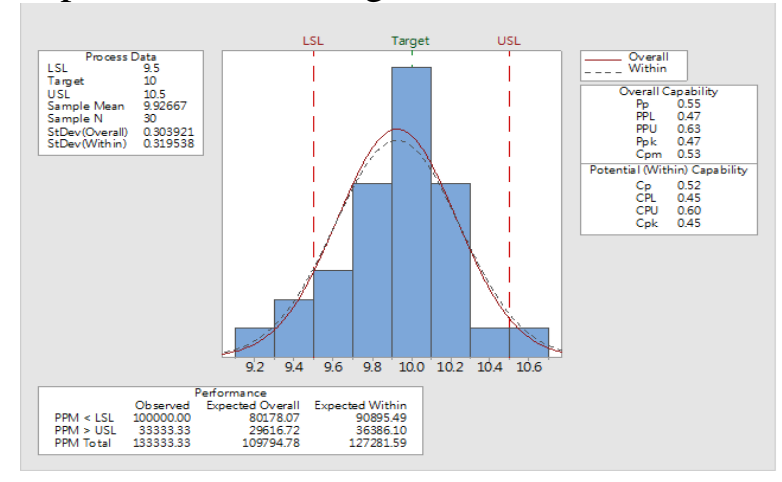

Figure 2. Process capability Cpk (before)

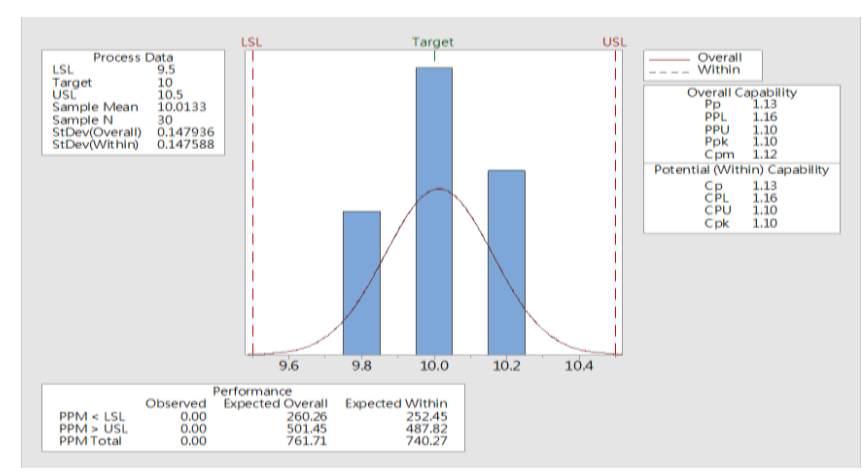

Figure 3. Process capability Cpk (after improvement) 
Analyze - Triz method is applied on analyze process, the analyzed results shown as Table 3. Principle 35 "Parameter Changes" is chosen to solve the problem.

Table 3 Matrix of contradiction of steel ball riveting

\begin{tabular}{|l|l|l|l|l|l|l|}
\hline \multicolumn{2}{|c|}{ worsen } & 1 & $\cdots$ & 13 & $\cdots$ & 39 \\
\cline { 2 - 6 } & $\begin{array}{l}\text { Weight of moving } \\
\text { object }\end{array}$ & $\cdots$ & $\begin{array}{r}\text { Length of } \\
\text { stationary }\end{array}$ & $\cdots$ & Productivity \\
\hline 4 & $\begin{array}{l}\text { Length of } \\
\text { stationary }\end{array}$ & & $35 \cdot 37 \cdot 39$ & & \\
\hline
\end{tabular}

Next step, we select Parameters and level to do experiment.

Table 4 Control Parameters and levels

\begin{tabular}{|c|c|c|c|}
\hline Control level & level1 & level 2 & level 3 \\
\hline A. Current (A) & 140 & 160 & 180 \\
\hline $\begin{array}{c}\text { B Speed } \\
(\mathrm{cm} / \mathrm{min})\end{array}$ & 30 & 40 & 50 \\
\hline C Voltage (V) & 14 & 16 & 18 \\
\hline
\end{tabular}

Improve - In this phase we have to deciding method of experiment and analyze experiment data. In this case, L9 orthogonal array forms appropriate choice as table 5.

Table 5 L9 and SN ratio

\begin{tabular}{|c|c|c|c|c|c|c|c|c|}
\hline N0. & Current & Speed & voltage & data1 & data 2 & data 3 & SNRA & MEAN \\
\hline 1 & 1 & 1 & 1 & 9 & 9.2 & 9 & 37.8996 & 9.0667 \\
\hline 2 & 1 & 2 & 2 & 9 & 9.2 & 9 & 37.8996 & 9.0667 \\
\hline 3 & 1 & 3 & 3 & 9 & 9.2 & 9 & 37.8996 & 9.0667 \\
\hline 4 & 2 & 1 & 2 & 11 & 10.8 & 10.6 & 34.6479 & 10.8000 \\
\hline 5 & 2 & 2 & 3 & 11 & 10.8 & 11 & 39.5257 & 10.9333 \\
\hline 6 & 2 & 3 & 1 & 11 & 10.4 & 10.6 & 30.8602 & 10.6667 \\
\hline 7 & 3 & 1 & 3 & 10.8 & 10.6 & 10.8 & 39.3653 & 10.7333 \\
\hline 8 & 3 & 2 & 1 & 11 & 10.6 & 10.8 & 34.6479 & 10.8000 \\
\hline 9 & 3 & 3 & 2 & 11 & 10.6 & 10.4 & 30.8602 & 10.6667 \\
\hline
\end{tabular}

Signal-to-Noise Ratio (SN ratio): By maximizing SN ratio, we can determine the best setting of control factors involved in this production process.

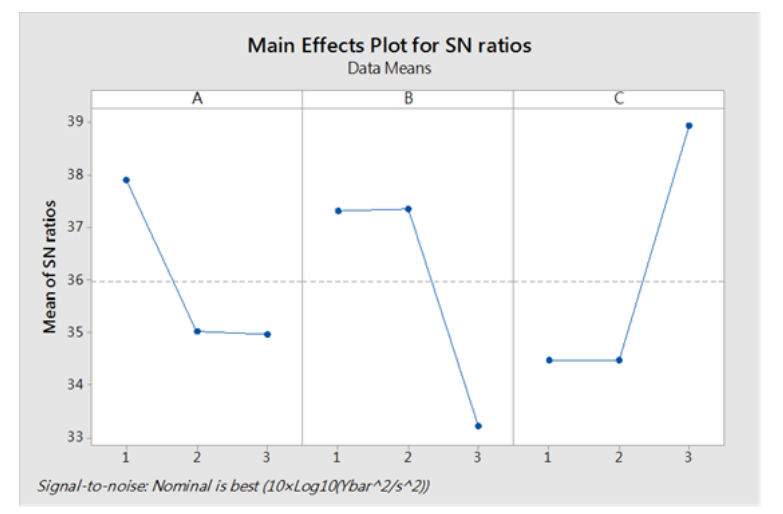

Figure 4. Main effects of SN ratios (before improved) 
Table 6 Average SN ratio of Parameters and levels

\begin{tabular}{|c|c|c|c|}
\hline Level & current $(\mathrm{A})$ & speed $(\mathrm{cm} / \mathrm{min})$ & voltage $(\mathrm{V})$ \\
\hline 1 & 37.90 & 37.30 & 34.47 \\
\hline 2 & 35.01 & 37.36 & 34.47 \\
\hline 3 & 34.96 & 33.21 & 38.93 \\
\hline Delta & 2.94 & 4.15 & 4.46 \\
\hline Rank & 3 & 2 & 1 \\
\hline
\end{tabular}

Table 730 PCS data from loading point of a bin shelving (after improved)

\begin{tabular}{|c|c|c|c|c|c|}
\hline 9.8 & 10 & 10 & 10 & 10.2 & 10 \\
\hline 10 & 10.2 & 10.2 & 10.2 & 10 & 10 \\
\hline 9.8 & 10 & 10 & 10 & 10.2 & 10.2 \\
\hline 10 & 9.8 & 9.8 & 9.8 & 10 & 9.8 \\
\hline 10 & 10.2 & 10 & 9.8 & 10.2 & 10.2 \\
\hline
\end{tabular}

\section{Conclusion}

In this study, TRIZ and Taguchi's method are used to find the best parameter setting for a bin shelving. The Process Capability Index (Cpk) value significantly increases from 0.53 to 1.12 . It means a significant improvement. This study first applies TRIZ to find out the hint of solving problem is to change parameter, and then used Taguchi's method to find the best setting parameters. Finally, we do experiment to examine the setting of control factors. The results of experiment in this case show that the best parameter levels can improve effectively production process.

\section{Reference}

[1] Lin, Y.H., Li, S.P., Lu, C.Y., Chung, R.G., Chen, D.F., " Research into the Improvement on Hexagonal Socket by Applying the System Innovation Theory" Advances in Engineering Research, Vols. 52, (2016), pp 55-57.

[2] Chang, C. P., Lin, Y.H. and Lu, C. Y. "Applying TRIZ Systematic Innovation Method to Improve Urinals", Advances in Engineering Research, Vols. 22, (2015), pp 793-795.

[3] Lee, R.S., Bakthavatsalam, R., Marsh, C.L. and Kuhr, C.S., "Ureteral Complications in Renal Transplantation: A Comparison of the Lich-Gregoir Versus the Taguchi Technique", Transplantation Proceedings Volume: 39, Issue: 5, (2007), pp.1461-1464.

[4] Hong, C. W., "Using the Taguchi method for effective market segmentation", Expert Systems with Applications Volume 39, Issue 5, (2012), pp 5451-5459.

[5] Chan, K. Y., Rajakaruna, N.; Engelke, U., Murray, I. and Abhayasinghe, N., "Alignment parameter calibration for IMU using the Taguchi method for image deblurring", Measurement Volume: 65, (2015), pp 207-219.

[6] Barry, Katie; Domb, Ellen; Slocum, Michael S. "Triz - What is Triz". The Triz Journal. Real Innovation Network.

[7] Sheng, I. L. S.; Kok-Soo, T. "Eco-Efficient Product Design Using theory of Inventive Problem Solving (TRIZ) Principles". American Journal of Applied Sciences. 7 (6): (2010), pp 852-858.

[8] https://en.wikipedia.org/wiki/Taguchi_methods.

[9] "What is Process Capability?" NIST/Sematech Engineering Statistics Handbook. National Institute of Standards and Technology. 